\title{
Machine Learning Approach to Predictive Maintenance in Manufacturing Industry - A Comparative Study
}

\author{
Dr. P. Karuppusamy, \\ Professor, \\ Department of EEE, \\ Shree Venkateshwara Hi-Tech Engineering College, \\ Erode, India. \\ Email: pkarrupusamy@ ieee.org
}

\begin{abstract}
Predictive maintenance is the way to improve asset management in every manufacturing industry. While handling advance costlier machinery in the industry, the predictive maintenance knowledge will be essential to protect the machinery before gets degradation performance. Recently, the emergence of business in manufacturing industry deals with good systems, regular intervals maintenance process, predictive maintenance (PdM), machine learning (ML) approaches are extensively applied for handling the health standing of business instrumentation. Now the digital transformation towards I4.0, data techniques, processed management and communication networks; it's doable to gather huge amounts of operational and processes conditions information generated type many items of kit and harvest information for creating an automatic fault detection and diagnosing with the aim to attenuate period of time and increase utilization rate of the parts and increase their remaining helpful lives. The predictive maintenance is inevitable for property good producing in I40. This paper aims to provide a comprehensive review of the recent advancements of metric capacity unit techniques wide applied to PdM for good producing in I4.0 by classifying the analysis consistent with metric capacity unit algorithms, ML class, machinery and instrumentation used device employed in information acquisition, classification of knowledge size and kind, and highlight the key contributions of the researchers and so offers pointers and foundation for additional analysis. In this research paper we constructed a Random Forest model to predict the failure of the various machine in manufacturing industry. It compares the prediction result with Decision Tree (DT) algorithm and proves its superiority in accuracy and precision.
\end{abstract}

Keywords: Industry 4.0, Analytic Models, Machine Learning, IIoT Sensors

\section{INTRODUCTION}

The predictive maintenance is the future scope of various industries for many reasons. The term "Industry 4.0 (or) I4.0" is deriving from "The Fourth Industrial Revolution" currently famous word among industries territory [1]. It is necessary to handling the industrial equipment very safely and it should be healthier in their status always. If they maintain the status is healthier, then they can increase manufacturing profit into double. The machine learning techniques have emerged as a promising tool in PdM application for good manufacturing in I4.0; so it's exaggerated attraction of authors/researchers throughout recent years [2]. Simple manufacturing company consist of various operation and process with cutting machine, induction motor with pumping system, refrigeration system, and little power generation unit by wind turbine and etc. The importance of predictive maintenance is that the industry consists of physical and digital system for the any production context currently. Also the selection of inappropriate predictive maintenance technique from wrong dataset and it leads to infeasible maintenance scheduling [3]. The Machine learning (ML) algorithm is mainly suitable to detect fault with the help of huge collected dataset. But its bit challenge task to select appropriate ML techniques in an industrial systems. The older lean management was limited problem finder for today's companies also it is struggling to drive better efficiency currently [4].

As shown in figure 1, they will fix the problem or defect once it breaks in ancient times. Then they maintain the machine with regular intervals checking. After that, predict the exactly when it will break and maintain accordingly with historical data. Recently, the machine itself decides how to avoid and providing warning symbol or alarm for predicted imminent failure in the machine with learning algorithm $[4,5]$. 


\section{REACTIVE}

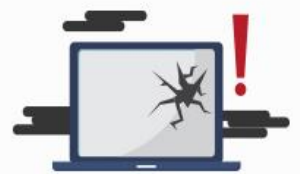

\section{PREVENTIVE}

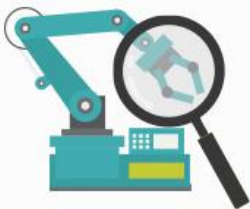

PREDICTIVE

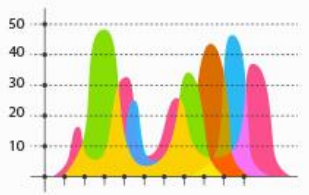

PRESCRIPTIVE

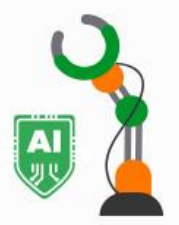

Figure 1 The evolution of maintenance strategies

Generally, the predictive maintenance is based on sensor measurement for e.g. temperature, pressure, vibration, rotation speeds, current, chemical properties of oil or water. Study of behavior of the system, current condition of the system, which parts of the machine are mostly failed many times, what will changes in the system due to temperature, vibration, pressure and etc. Not only these above said questions and many more intelligent version questions are better analytic results for predictive maintenance for machine [6, 7].

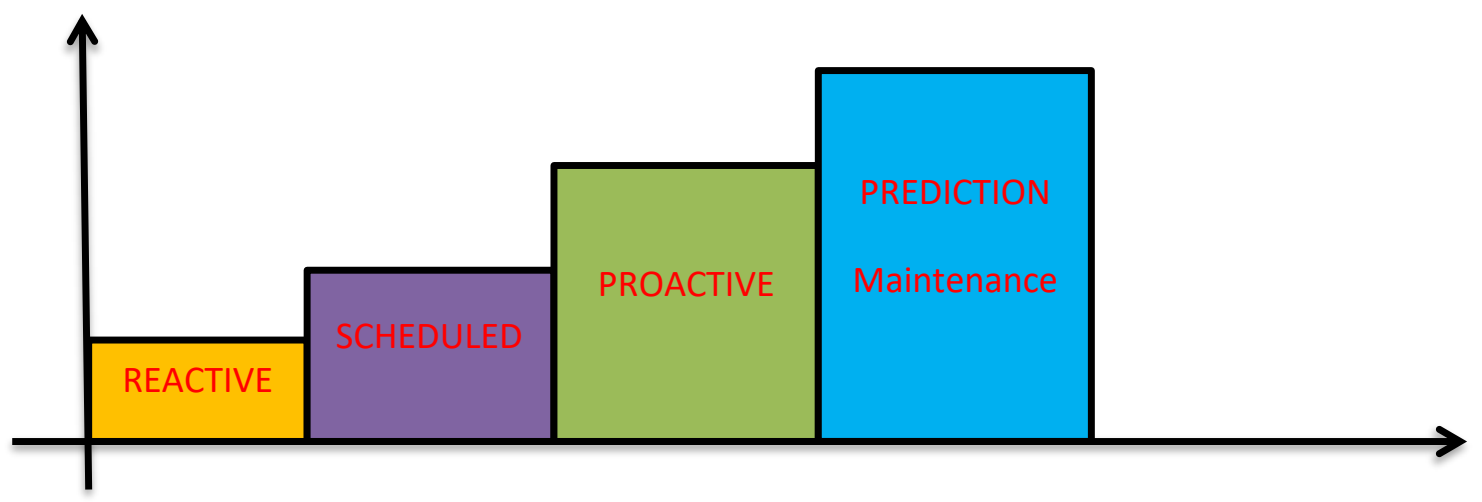

Figure 2 The stepping level of predictive maintenance

The figure 2 shows the level 4 can protect unpredictable failures more rather than previous level set of dataset. So the machine learning algorithms is essential tool to predict the efficient maintenance for machine now a day. During construction, catastrophic failures is one of the error which recovery impossible. The predictive maintenance is the only solution for this issue. The successful predictive maintenance systems are ensuring good accuracy and validity [8]. The maintenance of sensors, interface units (display, monitoring, and alarm) will be more constructive and systematic approach too. This predictive measure can create new era dashboard and indicators to run the manufacturing business in well manner $[9,10]$.

The vertical axis in the graphs shows reliability of the methods. The reliability is increasing technique by technique over the period. The horizontal axis in the graphs shows evaluation years. In an industry, the machines are repaired by reactive methods. The machine will be fixed after breakdown. So the overall product will be decreased. The various machines is having several type of achievement and work nature. Then they started to do scheduled maintenance activities. This method also wastes of human resources and time. Proactive method also lagging and fails in overall predicting the maintenance timing for any machine. Finally, predictive maintenance is an advanced analytics and sensing the data to detect the machine reliability.

\section{The benefits of predictive maintenance \\ Increasing machine useful life}

Due to set operation in an optimum setting, the machine breakdown reduces; causes it increases machine life. One of the stressful failures is asset failure in the system level. Due to operation reliable, the downtime of machine or system will be reduced. 
Journal of Soft Computing Paradigm (JSCP) (2020)

Vol.02/ No.04

Pages: 246-255

http://irojournals.com/jscp/

DOI: https://doi.org/10.36548/jscp.2020.4.006

\section{Reduced environment impact}

With the aid of collection of advance analytics, the machine operates for longer period so the system consumes fewer natural resources. Predictive maintenance is handling social responsibility very caring for the environment impact.

\section{Reduction of maintenance costs}

The sensor operations are very perfect and very efficient due to planning and scheduled maintenance provides less maintenance cost.

\section{Reduction in workers injuries}

Obviously, the reduced breakdowns will help to predict the sensor data perfectly which reduces worker injuries rate.

\section{Reduction in waste work in the system}

If the optimum operation is not happened for the system, the wasteful production will be a result or output. But predictive maintenance system can cover optimum operation due to advance analytics.

\section{Improved product quality}

The sensor data will be evaluated correctly by input algorithm can create and improve the product quality for longer time and get customer's worthy feedback.

\section{Increased performance over time}

The predictive maintenance systems are operating based on knowledge or intelligent based learning systems. So, the decision making technique will improve overall performance on over time implicit. The predictive maintenance applications are implementing on automotive, airlines, high-tech manufacturing, transportation, harbor port that industries are gaining those benefits directly. These industries are directly related or dealing with monitoring sensor data $[11,12]$.

There are lots of advantages of predictive maintenance from cost saving sector and it includes minimizing planned downtime of the system lifespan. Also, the amount of time it takes to assess and implement a predictive maintenance schedule.

\section{ORGANIZATION OF THE RESEARCH}

The structure of the research article organized as follows; Section 3 gives literature survey of recent predictive maintenance program and its approach. Section 4 provides the description of theoretical analysis. Section 5 delivers description of results and discussion finally the conclusion and further improvement is in section 6 .

\section{PRELIMINARIES}

Sathish \& Smys says about smart agriculture, living, parking, cities, industry as well as environment. The industry consists of explosive type of gas and material which should be monitored and controlled very carefully. This maintenance and repair should be in early and predictive maintenance assigned for a particular failure which is not reversible [1]. Farahani \& Firouzi et al proposes use of machine learning analytics with huge amount of data from the Internet of Things (IoT) sensors and it is controlled distributed the application into various manufacturing industry sector. They mainly focuses predict the failure in the system in advance, therefore increasing machine useful lifespan. Also they indicate about predictive maintenance research is in still preliminary level in manufacturing industry [13]. Chiang \& Zhang concentrates oil and gas industry in manufacturing unit [14].

Lee, Ghaffari \& Elmeligy research focuses a Condition Based Maintenance (CBM) strategy which is in earlier techniques for predictive method. Previous revolution in industry mostly, the system used to detect any failures beforehand with the aid of Preventive Maintenance (PM) strategies [15]. Selcuk research gave that the importance of Predictive Maintenance in terms of improving reliability, efficiency and prefer green environment [16]. Civerchia et al introduces system and component architecture of Industry Internet of Things (IIoT) sensor and it is detailed described [17]. Mourtzis et al discuss about predictive Maintenance and IoT applications with IIoT

ISSN: 2582-2640 (online) 
Journal of Soft Computing Paradigm (JSCP) (2020)

Vol.02/ No.04

Pages: 246-255

http://irojournals.com/jscp/

DOI: https://doi.org/10.36548/jscp.2020.4.006

sensor architecture. The work focuses IoT wireless sensor network is working for industrial applications which maintains with huge volume of dataset for efficient analysis about the machine [18]. Wang proposes zero defect manufacturing in an industry with the aid of predictive maintenance technique. Moreover, the author discuss about predictive maintenance consists of number of activities which will be in the dataset. This can help to detect the changes in physical state of machine that choose appropriate maintenance work for equipment failure. This will lead to increase the performance over time. This allotment of appropriate maintenance work is in view of intelligent predictive Maintenance framework. Mainly, the author focuses an optimal prediction of machinery failures using huge volume of dataset from IIoT sensors [19].

The above said research articles are perfect class in proactive, scheduled maintenance analysis. Also the algorithm is very inefficient in predictive maintenance schedule. There is research gap being there that lack of this machine predicting its failure and protecting. We developed a model and conducted several test with the help of learning algorithm for industrial machinery. The main goal of this research study is to discover defect in the various machine parts with the ML techniques in an industry.

\section{THEORETICAL ANALYSES}

The cloud computing will be more smarter while using machine learning techniques in that. The machine learning techniques are very simple and popular to handle the data in cloud. In this research paper focuses AutoML (automated Machine Learning) for the process in real and practical environment. The AutoML consist of two main aspects named data collection and prediction. The machine process will be optimized due to AutoML after parameter tuning. Here automated feature detection and selection has happening after the data preprocessed from dataset. But each step is controlled and performing manually with the reference from previous one [20, 21, 22]. Currently, the ML technique has operated in wider range application in manufacturing industry. Because of this ML algorithm provide better support for any kind of manufacturing industry always. Obviously, we can reduce part of manpower in any industry with increasing efficiency. In this research papers, the Bayes naive algorithm is used in parameter tuning process to give efficient computing power.

\subsection{Important Units}

IIoT Sensors

Many sensors are operated as IIoT which is used for interact and communicate with cyber physical systems. Some of the sensors measures temperature, pressure, electrical quantities, vibration, and humidity. The output of sensors can be conditioned by signal conditioner unit in our proposed model. The more number of IIoT sensors uses for many varieties of application targets such as air, gas, any liquid quality measures; also ultrasonic sound sensor is used to measure many leakages in tank which is in industry for many purposes [23, 24].

\section{Signal Conditioning Unit}

Generally, this unit is making a signal in appropriate format for next section which will connect with signal conditioning unit. The capturing signals are taken as data and convert into binary format using Analog-Digital Converter (ADC). For further analysis, the signals should be in digital format. It is shown in the proposed system architecture in the figure 5.

\section{Data Creation \& Communication}

There must be a database file which is remotely centralized. Because of the IoT sensors are located different locations and installed in remote location without internet connection.

\section{Extension of cloud computing}

The predictive maintenance is computed by edge or cloud. The edge computing is local network level which is used to provide real time machine failure. Normally, the cloud computing is having big data center that is located in centralized. The IoT sensors are providing data for further processing to clouds. Usually, the latency problems arise in cloud computing which is mitigated by fog architecture implementation over the cloud which is shown in figure 3.

ISSN: 2582-2640 (online) 
Journal of Soft Computing Paradigm (JSCP) (2020)

Vol.02/ No.04

Pages: 246-255

http://irojournals.com/jscp/

DOI: https://doi.org/10.36548/jscp.2020.4.006

\section{Labeled Observation}

The labeled data is having form of training set and test set for the classification by machine learning algorithm. Based on the error, the labeled data will be countable and give feedback for the prediction process [25, $26,27,28]$.

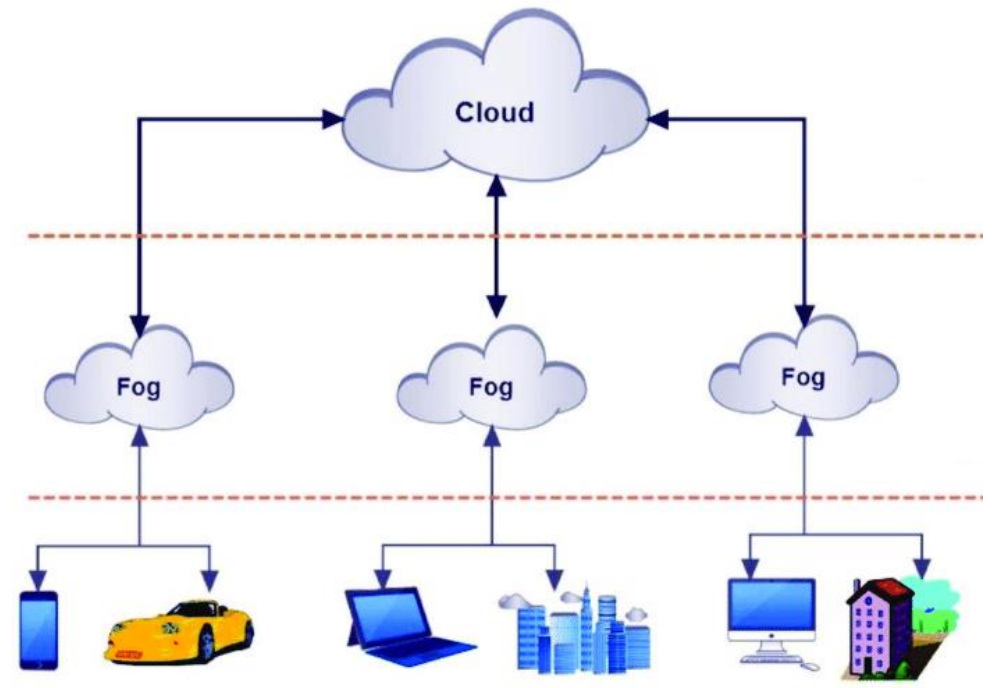

Figure 3 Fog computing between cloud and end devices

\subsection{Proposed Predictive Maintenance model}

\subsubsection{Decision Tree (DT)}

Decision Tree is a network devices that consists of branch which is connected many nodes as shown in figure 4 . The nodes are classified into two types.

1. Root nodes

2. Intermediate nodes

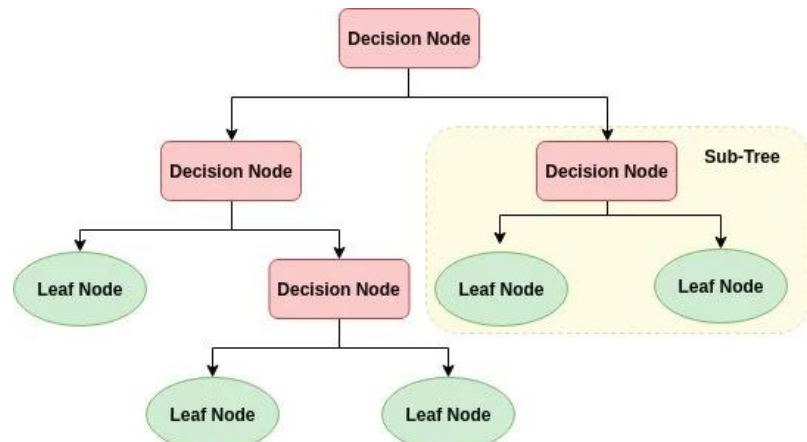

Figure 4 Overview of DT based Predictive Maintenance

The root nodes are used as backbone of the network system. The intermediate nodes are used to connect between root nodes and leaf nodes. This type of nodes is used to represent the features. Also it is named as decision nodes. 
Journal of Soft Computing Paradigm (JSCP) (2020)

Vol.02/ No.04

Pages: 246-255

http://irojournals.com/jscp/

DOI: https://doi.org/10.36548/jscp.2020.4.006

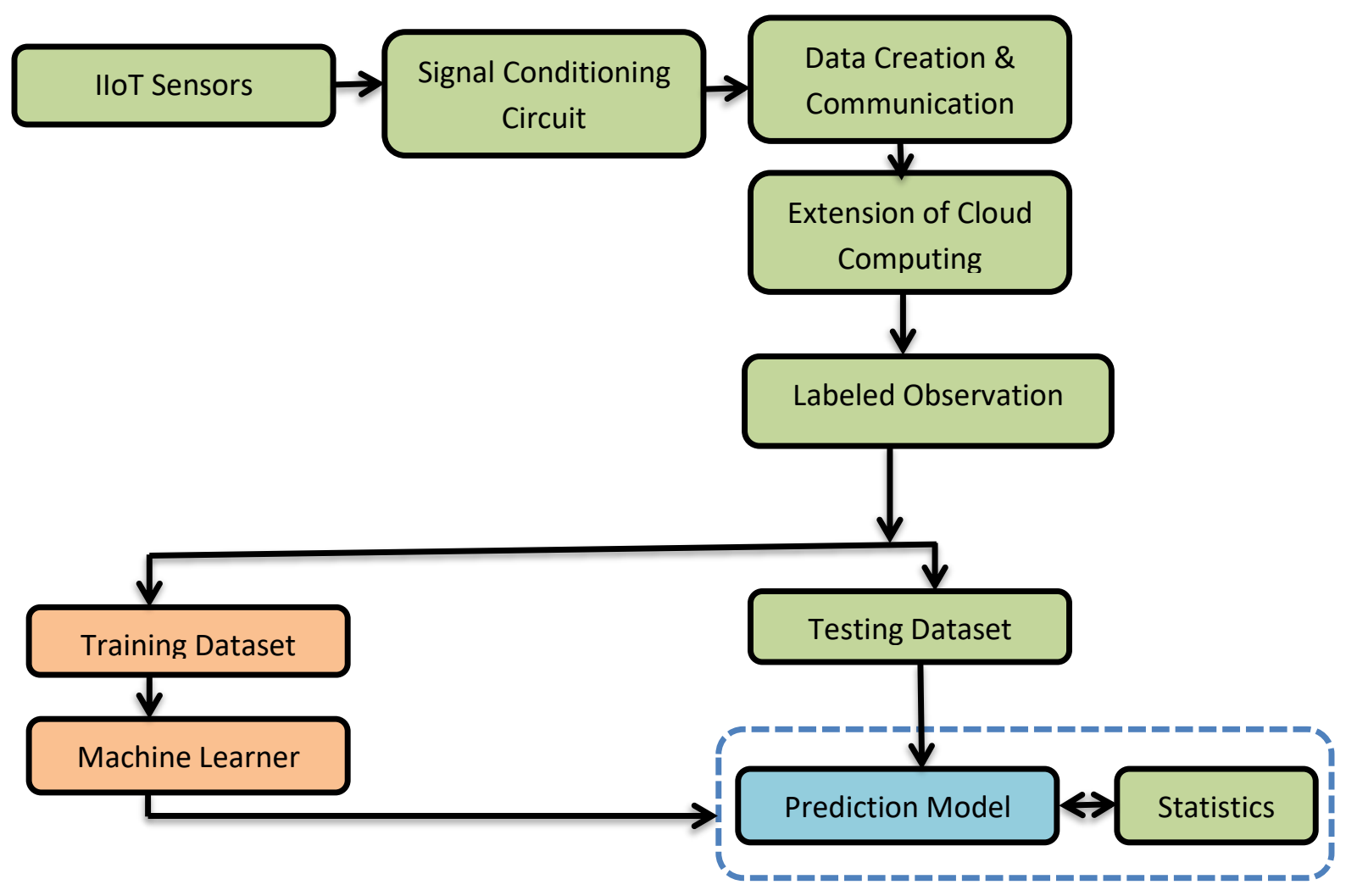

Figure 5 Overview of system architecture for Predictive Maintenance

\subsubsection{Random Forest (RF)}

This algorithm is one of the better accuracy wise result algorithms among supervised classification algorithm in an industry sector computation. This algorithm used to create forest and select it as random from that. The result will be more accurate while it contains larger number of trees. The Random Forest algorithm is used to find the root node and splitting the feature nodes randomly. Also this algorithm comprises of several DT classifiers and it contains many nodes. This prediction always based on tree predictions and our prediction RF model is constructed as shown in figure 6.

Our study is focusing the predicting the machine's imminent failure in the real-time in an industry with the help of Random Forest (RF model. There are number of metrics analyzed to compute the algorithm capability. Many ML algorithms can predict the healthier of the machine. It includes Linear Regression (LR), RF and Symbolic Regression (SR). 
Journal of Soft Computing Paradigm (JSCP) (2020)

Vol.02/ No.04

Pages: 246-255

http://irojournals.com/jscp/

DOI: https://doi.org/10.36548/jscp.2020.4.006
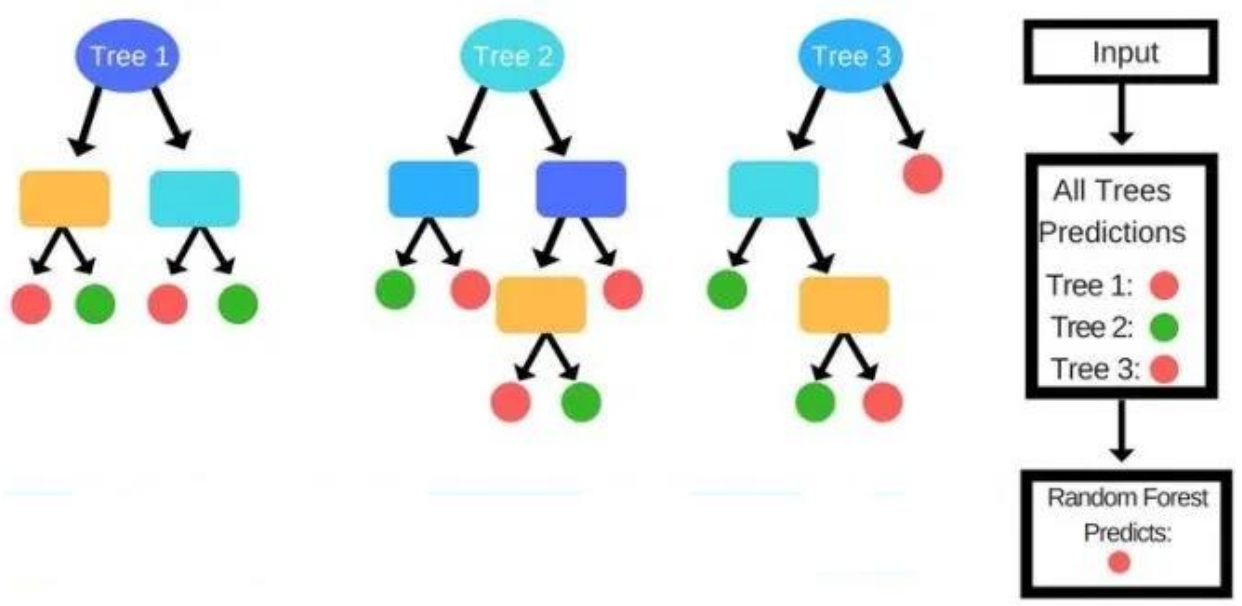

Figure 6 Random Forest machine learning algorithm

There are many detecting methods that drifting behavior in the data stream, lack of continues data stream, variation in vibration measurement and thermal imaging data, abrupt changes in sensor data in continues monitoring sensor streams. From the real data, our consideration is that rotating machinery in an industry. The RF algorithm is used as the multi sensor system for rotating machinery using feature fusion method. Also this technique can compensate the short comings of the heat or vibrations. It will provide the significant changes in the machine or sensor performance also its detection unit. For the industry pumps, the RF algorithm considering real data type is used to predict the failure of it. Also this can detect faults in vibration data in the machine data sets. The proposed model was validated using from few months monitoring data sets of the machine. For the cutting machine in the industry, model can evaluate its vibration measurement and thermal imaging data of it. Also it provides high accuracy result in final. For all type of refrigeration systems, monitoring the temperature sensor changes and it is validated with real data.

\section{RESULT DISCUSSIONS}

The obtained result has shown and discuss in table 1 . The rotating machines are evaluated by the feature fusion measurement for fault detection. This technique provides the result based on vibration data driven features. These extracted features are providing fault detection with moderate accuracy from an individual sensor streams. The transient current signal are evaluating for the induction motor status. These features are extracted and to determine the fitness of the machine. Also this double classifier approach is preferred for detect fault in the machine with the help of current and voltage waveform characteristic. 
Journal of Soft Computing Paradigm (JSCP) (2020)

Vol.02/ No.04

Pages: 246-255

http://irojournals.com/jscp/

DOI: https://doi.org/10.36548/jscp.2020.4.006

Table 1 The summary of obtained results

\begin{tabular}{|c|c|c|c|c|c|c|c|}
\hline \begin{tabular}{c|} 
ML \\
Technique
\end{tabular} & $\begin{array}{c}\text { Equipment } \\
\text { System }\end{array}$ & \begin{tabular}{c|} 
Prediction \\
Maintenance \\
Data Description
\end{tabular} & Data Size & Precision & Accuracy & $\begin{array}{c}\text { Pre- } \\
\text { identification }\end{array}$ & Reason \\
\hline $\begin{array}{l}\text { Random } \\
\text { Forest }\end{array}$ & $\begin{array}{l}\text { Industrial } \\
\text { Pump }\end{array}$ & $\begin{array}{l}\text { Industrial Pump } \\
\text { vibration data }\end{array}$ & $\begin{array}{l}1052 \text { features } \\
\text { from } 20 \text { various } \\
\text { industrial pump }\end{array}$ & $79 \%$ & $82 \%$ & $\begin{array}{c}\text { Above } \\
\text { Partially } \\
\text { predicted }\end{array}$ & $\begin{array}{l}\text { Can detect the faults from } \\
\text { vibration data that provide } \\
\text { moderate results }\end{array}$ \\
\hline $\begin{array}{l}\text { Random } \\
\text { Forest }\end{array}$ & $\begin{array}{l}\text { Industrial } \\
\text { Cutting } \\
\text { machine }\end{array}$ & $\begin{array}{l}\text { Communication } \\
\text { protocol sensor } \\
\text { data set }\end{array}$ & $\begin{array}{l}8345 \text { data from } \\
\text { cutting machine }\end{array}$ & $91 \%$ & $94 \%$ & Predicted & $\begin{array}{l}\text { Yes, provides good high } \\
\text { accuracy \& precision }\end{array}$ \\
\hline $\begin{array}{c}\text { Random } \\
\text { Forest }\end{array}$ & $\begin{array}{c}\text { Refrigerati } \\
\text { on based } \\
\text { system }\end{array}$ & $\begin{array}{l}\text { Temperature } \\
\text { sensor output }\end{array}$ & $\begin{array}{l}2125 \text { ( } 2 \text { Months } \\
\text { data set) }\end{array}$ & $89 \%$ & $92 \%$ & Predicted & $\begin{array}{l}\text { Yes, early pre identification } \\
\text { possible. }\end{array}$ \\
\hline $\begin{array}{c}\text { Random } \\
\text { Forest }\end{array}$ & $\begin{array}{l}\text { Induction } \\
\text { Motor, } \\
2.2 \mathrm{~kW}\end{array}$ & $\begin{array}{l}\text { Voltage, current } \\
\text { waveform data }\end{array}$ & $\begin{array}{l}1021 \text { three } \\
\text { phases dataset }\end{array}$ & $72 \%$ & $74 \%$ & $\begin{array}{l}\text { Above } \\
\text { partially } \\
\text { Predicted }\end{array}$ & $\begin{array}{l}\text { Analyzed with single \& } \\
\text { double classifier approach. } \\
\text { Offers double classifier } \\
\text { approach for better results }\end{array}$ \\
\hline $\begin{array}{c}\text { Random } \\
\text { Forest }\end{array}$ & $\begin{array}{l}\text { Wind } \\
\text { Turbine }\end{array}$ & $\begin{array}{c}\text { Alarm type \& } \\
\text { Operational data } \\
\text { set for } 17 \text { turbine }\end{array}$ & $\begin{array}{l}348 \text { alarm types } \\
\& 84 \text { operational } \\
\text { data }\end{array}$ & $61 \%$ & $65 \%$ & $\begin{array}{l}\text { Partially } \\
\text { Predicted }\end{array}$ & $\begin{array}{l}\text { A front end where the status } \\
\text { of turbine can be visualize } \\
\text { in real-time. }\end{array}$ \\
\hline
\end{tabular}

The refrigeration systems are in many supermarket as well as chemical industry. In order to predict the fault occurrence in the machine, the algorithm can detect the fault early and validated with real time data with 2125 different refrigerator. The model achieved pre identification and good precision, accuracy. It will find more beneficial such as preventive maintenance and proactive scenario for many industries.

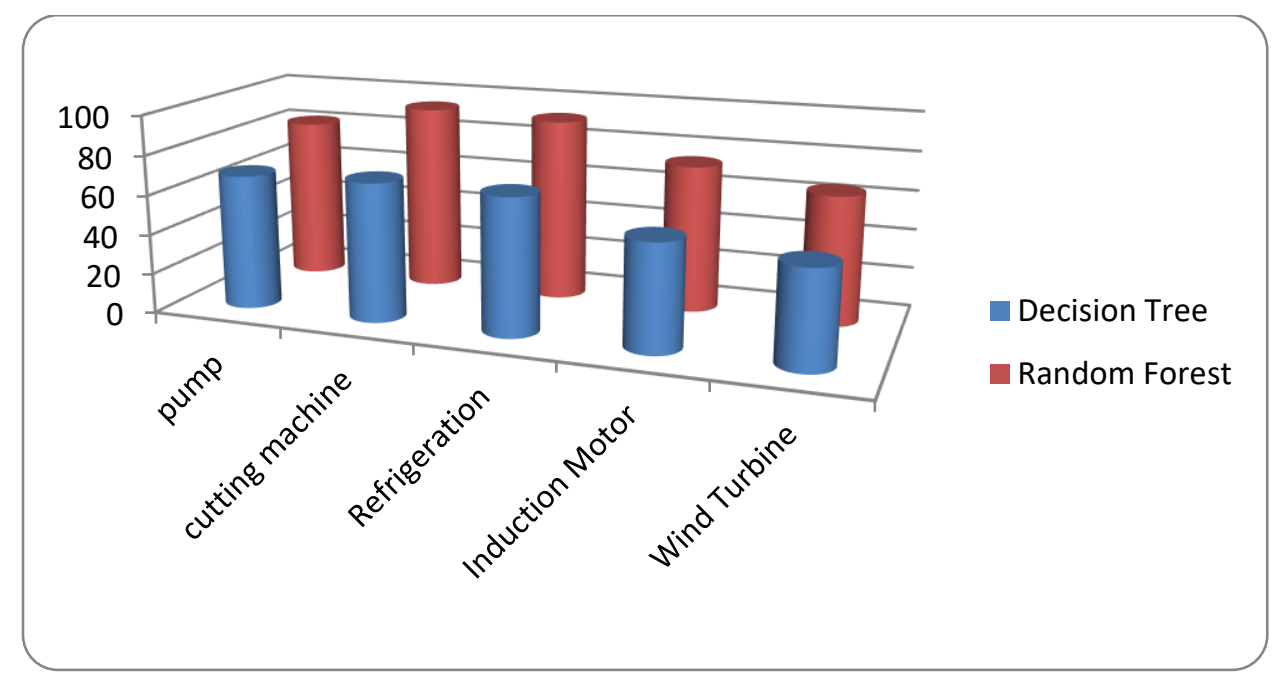

Figure 7 Accuracy evaluation chart

From the industrial cutting machinery dataset, the algorithm model can predict exact faultiness of the machine due to high amount of features from the dataset. The industrial pump can predict faultiness from sensor vibration data and provide high accuracy nearly. Moreover, the decision tree algorithm model is lesser in all aspects

ISSN: 2582-2640 (online) 
Journal of Soft Computing Paradigm (JSCP) (2020)

Vol.02/ No.04

Pages: 246-255

http://irojournals.com/jscp/

DOI: https://doi.org/10.36548/jscp.2020.4.006

compared to RF model algorithm. DT model is an unstable that cannot withstand small changes in dataset which is acquired from an industry. They are relatively inaccurate with prediction during changes in dataset in real-time. It shows in the graph figure 7.

\section{CONCLUSION}

This research article present a review of RF and DT methods of machine learning algorithm applies in various parts of manufacturing industry. Finally constructed RF and tested successfully with various metric measurements. The discussion and literature review also was performed. The determining machine failure is a primary goal of predictive maintenance. All the sensors data sent and processing by learning algorithm for predict the machine failure. The given data is preprocessed because of the real time data. These data is collected directly from sensor with raw. So the data are not clean and ordered. The cleaning data carried out for further process which provides higher reliability and accuracy of prediction. Also this data are splitting into two for training and testing. With the help of these dataset, there can create predictive maintenance model. The output from the constructed model will be analyzed and evaluated. The accuracy and precision will be fewer in some period of predictive time. The deep logical analysis of the key demanding situations is challenging task as our future enhancement of our research article. Also the various segments in manufacturing industry and minimum predictive maintenance data size will provide less accuracy and precise for predictive maintenance.

Also we recommend do furthering improvements and motivating authors and researchers for the following aspects;

1. The optimum preprocessing technique should be used for raw data analysis to get better accuracy.

2. Combine two or more ML techniques to design the model to achieve better prediction for data acquisition.

3. Machine Learning model approach can be extended for further studied.

4. Classification and anomaly detection algorithms will be combined to keep up exactness of the classification models while not losing anomaly detection benefits. By this manner, PdM can be applied to instrumentality or system that doesn't have giant data.

\section{ACKNOWLEDGEMENT}

We are most grateful to Eng. Mussie, (Retired) Ministry of Telecommunication, Department of Electrical \& Electronics Engineering, Mainefhi College of Engineering, for his assistance and encourage this research.

\section{REFERENCES}

[1] Sathish and Smys "A Survey on Internet of Things (IoT) based Smart Systems" Journal of ISMAC (2020) Vol.02/ No.04 Pages: 181-189, http://irojournals.com/iroismac/ DOI: https://doi.org/10.36548/jismac.2020.4.001

[2] Carvalho, T.P.; Soares, F.A.; Vita, R.; Francisco, R.D.; Basto, J.P.; Alcalá, S.G. A systematic literature review of machine learning methods applied to predictive maintenance. Comput. Ind. Eng. 2019, 137, 106024.

[3] Cinar, Z.M.; Nuhu, A.A.; Zeeshan, Q.; Korhan, O. Digital Twins for Industry 4.0: A Review. In Industrial Engineering in the Digital Disruption Era. GJCIE 2019. Lecture Notes in Management and Industrial Engineering; Calisir, F., Korhan, O., Eds.; Springer: Cham, Switzerland, 2020.

[4] Zhang, W.; Yang, D.; Wang, H. Data-Driven Methods for Predictive Maintenance of Industrial Equipment: A Survey. IEEE Syst. J. 2019, 13, 2213-2227.

[5] Borgi, T.; Hidri, A.; Neef, B.; Naceur, M.S. Data analytics for predictive maintenance of industrial robots. In Proceedings of the 2017 International Conference on Advanced Systems and Electric Technologies (IC_ASET), Hammamet, Tunisia, 14-17 January 2017; pp. 412-417.

[6] Dai, X.; Gao, Z. From model, signal to knowledge: A data-driven perspective of fault detection and diagnosis. IEEE Trans. Ind. Inform. 2013, 9, 2226-2238.

[7] Lee, J.; Lapira, E.; Bagheri, B.; Kao, H.A. Recent advances and trends in predictive manufacturing systems in big data environment. Manuf. Lett. 2013, 1, 38-41.

[8] Peres, R.S.; Rocha, A.D.; Leitao, P.; Barata, J. IDARTS-Towards intelligent data analysis and real-time supervision for industry 4.0. Comput. Ind. 2018, 101, 138-146.

[9] Sezer, E.; Romero, D.; Guedea, F.; MacChi, M.; Emmanouilidis, C. An Industry 4.0-Enabled Low Cost Predictive Maintenance Approach for SMEs. In Proceedings of the 2018 IEEE International Conference on Engineering, Technology and Innovation (ICE/ITMC), Stuttgart, Germany, 17-20 June 2018; pp. 1-8.

ISSN: 2582-2640 (online) 
Journal of Soft Computing Paradigm (JSCP) (2020)

Vol.02/ No.04

Pages: 246-255

http://irojournals.com/jscp/

DOI: https://doi.org/10.36548/jscp.2020.4.006

[10] Biswal, S.; Sabareesh, G.R. Design and development of a wind turbine test rig for condition monitoring studies. In Proceedings of the 2015 International Conference on Industrial Instrumentation and Control (ICIC), Pune, India, 28-30 May 2015; pp. 891-896.

[11] Amruthnath, N.; Gupta, T. A research study on unsupervised machine learning algorithms for early fault detection in predictive maintenance. In Proceedings of the 2018 5th International Conference on Industrial Engineering and Applications, ICIEA, Singapore, 26-28 April 2018; pp. 355-361.

[12] Yoo, Y.; Park, S.H.; Baek, J.G. A Clustering-Based Equipment Condition Model of Chemical Vapor Deposition Process. Int. J. Precis. Eng. Manuf. 2019, 20, 1677-1689.

[13] Farahani, B., Firouzi, F., Chang, V., Badaroglu, M., Constant, N., \& Mankodiya, K. (2018). Towards fogdriven IoT eHealth: Promises and challenges of IoT in medicine and healthcare. Future Generation Computer Systems, 78, 659-676.

[14] Chiang, M., \& Zhang, T. (2016). Fog and IoT: An overview of research opportunities. IEEE Internet of Things Journal, 3(6), 854-864.

[15] Lee, J., Ghaffari, M., \& Elmeligy, S. (2011). Self-maintenance and engineering immune systems: Towards smarter machines and manufacturing systems. Annual Reviews in Control, 35(1), 111-122.

[16] Selcuk, S. (2017). Predictive maintenance, its implementation and latest trends. Proceedings of the Institution of Mechanical Engineers, Part B: Journal of Engineering Manufacture, 231(9), 1670-1679.

[17] Civerchia, F., Bocchino, S., Salvadori, C., Rossi, E., Maggiani, L., \& Petracca, M. (2017). Industrial Internet of Things monitoring solution for advanced predictive maintenance applications. Journal of Industrial Information Integration, 7, 4-12.

[18] Mourtzis, D., Vlachou, E., \& Milas, N. (2016). Industrial Big Data as a result of IoT adoption in manufacturing. Procedia cirp, 55, 290-295.

[19] Wang, K. (2016). Intelligent predictive maintenance (IPdM) system-Industry 4.0 scenario. WIT Transactions on Engineering Sciences, 113, 259-268.

[20] Susto, G.A.; Schirru, A.; Pampuri, S.; McLoone, S.; Beghi, A. Machine learning for predictive maintenance: A multiple classifier approach. IEEE Trans. Ind. Inform. 2015, 11, 812-820.

[21] Susto, G.A.; Beghi, A.; De Luca, C. A predictive maintenance system for epitaxy processes based on filtering and prediction techniques. IEEE Trans. Semicond. Manuf. 2012, 25, 638-649.

[22] Ahmad, R.; Kamaruddin, S. An overview of time-based and condition-based maintenance in industrial application. Comput. Ind. Eng. 2012, 63, 135-149.

[23] Mathew, V.; Toby, T.; Singh, V.; Rao, B.M.; Kumar, M.G. Prediction of Remaining Useful Lifetime (RUL) of turbofan engine using machine learning. In Proceedings of the 2017 IEEE International Conference on Circuits and Systems (ICCS), Thiruvananthapuram, India, 20-21 December 2017; pp. 306-311.

[24] Samuel, A.L. Some studies in machine learning using the game of checkers. IBM J. Res. Dev. 2000, 44, 206226.

[25] Rivera Torres, P.J.; Serrano Mercado, E.I.; Llanes Santiago, O.; Anido Rifón, L. Modeling preventive maintenance of manufacturing processes with probabilistic Boolean networks with interventions. J. Intell. Manuf. 2018, 29, 1941-1952.

[26] Jezzini, A.; Ayache, M.; Elkhansa, L.; Makki, B.; Zein, M. E_ects of predictive maintenance(PdM), Proactive maintenace $(\mathrm{PoM})$ \& Preventive maintenance $(\mathrm{PM})$ on minimizing the faults in medical instruments. In Proceedings of the 2013 2nd International Conference on Advances in Biomedical Engineering, Tripoli, Lebanon, 11-13 September 2013; pp. 53-56.

[27] Kumar, A.; Chinnam, R.B.; Tseng, F. An HMM and polynomial regression based approach for remaining useful life and health state estimation of cutting tools. Comput. Ind. Eng. 2019, 128, 1008-1014.

[28] Munirathinam, S.; Ramadoss, B. Big data predictive analtyics for proactive semiconductor equipment maintenance. In Proceedings of the 2014 IEEE International Conference on Big Data (Big Data), Washington, DC, USA, 27-30 October 2014; pp. 893-902.

ISSN: 2582-2640 (online) 